Ivanovska, V., Hek, K., Mantel-Teeuwisse, A.K., Leufkens, H.G.M., Dijk, L. van. Age-specific antibiotic prescribing and adherence to guidelines in pediatric patients in primary care.

\begin{tabular}{|l|l|}
\hline $\begin{array}{l}\text { Postprint } \\
\text { Version }\end{array}$ & 1.0 \\
\hline Journal website & $\frac{\text { http://journals.Iww.com/pidj/Abstract/publishahead/Age Specific Antibiotic Presc }}{\text { ribing and Adherence.96905.aspx }}$ \\
\hline Pubmed link & $\underline{\text { https://www.ncbi.nlm.nih.gov/pubmed/28859019 }}$ \\
\hline DOI & $10.1097 /$ INF.0000000000001757 \\
\hline
\end{tabular}

This is a NIVEL certified Post Print, more info at http://www.nivel.eu

\title{
Age-Specific Antibiotic Prescribing and Adherence to Guidelines in Pediatric Patients in Primary Care
}

\author{
Verica IVANovska, MPH, PHD ${ }^{1}$, Karin HeK, PHD ${ }^{2}$, AukJe K.MANTEl-TeEuwisse, \\ PharmD, PhD ${ }^{1}$, Hubert G. M.LeufKens, PhARmD, PhD ${ }^{1,3}$, AND Liset VAN DiJK, HhD $^{2}$ \\ ${ }^{1}$ Utrecht Institute for Pharmaceutical Sciences, Utrecht University, Utrecht, the Netherlands; \\ ${ }^{2}$ NIVEL, Netherlands Institute for Health Services Research, Utrecht, the Netherlands; \\ ${ }^{3}$ Medicines Evaluation Board, the Netherlands \\ Background
}

Most antibiotics in children are used to treat viral and self-limiting conditions. This study aims to compare physicians' adherence to guidelines on antibiotic prescribing in fever and in ear and respiratory infections to children in different age groups in the Netherlands.

Methods

Data were used from the NIVEL Primary Care Database. For all pediatric episodes of fever, acute otitis media (AOM), streptococcal pharyngitis (strep throat), sinusitis, acute tonsillitis, acute bronchitis/bronchiolitis and pneumonia in 2012, we determined whether national guidelines were followed in regard to whether an antibiotic was prescribed, and the type of antibiotic.

Results

For diagnoses that generally do not require antibiotics, more prescriptions were found in adolescents' episodes compared with children aged 0-4 and 5-11 years, respectively, (bronchitis: $52.0 \%$ vs. $42.4 \%$ and $42.7 \%$, and fever: $16.8 \%$ vs. $9.0 \%$ and $14.2 \%$ ). The same was true for diagnoses that require antibiotics (strep throat: $76.5 \%$ vs. $55.0 \%$ and $49.5 \%$, pneumonia: $71.6 \%$

vs. $60.2 \%$ and $69.8 \%$, and tonsillitis: $57.8 \%$ vs. $54.8 \%$ and $49.7 \%$ ), except for AOM (43.9\% vs. $52.4 \%$ and $39.6 \%)$. First-choice amoxicillin was prescribed more frequently in children 0-4 years of age than in age groups 5-11 and 11-17 years (AOM: $88.0 \%$ vs. $83.2 \%$ and $81.8 \%$, and pneumonia: $74.7 \%$ vs. $57.2 \%$ and $53.8 \%$ ). First-choice narrow-spectrum penicillins were prescribed more often in 
Ivanovska, V., Hek, K., Mantel-Teeuwisse, A.K., Leufkens, H.G.M., Dijk, L. van. Age-specific antibiotic prescribing and adherence to guidelines in pediatric patients in primary care.

adolescents than in age groups 0-4 and 5-11 years (strep throat: $72.0 \%$ vs. $63.6 \%$, and $60.9 \%$, and tonsillitis: $67.9 \%$ vs. 33.1 and $45.9 \%$ ).

Conclusions

Adherence patterns demonstrated include high antibiotic rates for bronchitis, particularly in adolescents, and underuse of narrow-spectrum penicillins in the $0-4$ years group.

\section{INTRODUCTION}

Antibiotics are the most common medicines prescribed for children in primary care. ${ }^{1}$ The majority of pediatric antibiotics are used to treat fever, ear and respiratory tract infections (RTI), due to fears of serious bacterial complications, although these conditions are often viral in origin and self-limiting. ${ }^{2-4}$

With antimicrobial resistance on the rise worldwide, it is advised that physicians prescribe antibiotics in accordance with evidence-based guidelines. ${ }^{5-7}$ Where relevant, guidelines for antibiotic therapy also consider the age of the patient, along with the illness severity and the presence of underlying diseases. Advice may be agespecific if treatment evidence differs across pediatric age groups. The relationship between age and consultation rates has been reported; children younger than 5 years have respiratory symptoms more frequently and consult their physicians more often than older ones. ${ }^{8,9}$ Moreover, RTI etiologies are frequently age- dependent, and different causative organisms, such as bacteria or viruses, can be found in younger and older children. ${ }^{10}$ Also, the prevalence of antibiotic prescribing in childhood varies

across age, with preschool children being mostly exposed to antibiotics. ${ }^{11}$

Relative to other countries, the Netherlands has low rates of antibiotic use. ${ }^{12}$ Yet, despite recommendations for restrictive antibiotic prescribing for RTIs, recent research has revealed potential areas of concern in primary care. ${ }^{13}$ Namely, $40 \%$ of acute bronchitis episodes in Dutch children were treated with antibiotics contrary to the advice to avoid them, and first-line narrow- spectrum penicillins were used less than recommended. ${ }^{13}$

There is clearly room for improvement, and an analysis of antibiotic prescribing by age may help in identifying age groups with potential inappropriate antibiotic exposure. But, limited knowledge is available on patterns of antibiotic use in children according to both their age and clinical condition.

The purpose of our study was to compare the adherence to guidelines on antibiotic prescribing in fever, ear infections and RTIs between children having different ages. We aimed to determine antibiotic prescribing patterns for children stratified by age, both in terms of degree of prescribing per diagnosis and choice of antibiotics.

\section{METHODS}

Data for 2012 used in this study were derived from the NIVEL Primary Care Database (NIVEL PCD), which collects routine electronic health records from 
Ivanovska, V., Hek, K., Mantel-Teeuwisse, A.K., Leufkens, H.G.M., Dijk, L. van. Age-specific antibiotic prescribing and adherence to guidelines in pediatric patients in primary care.

general practitioners (GP) across the Netherlands. ${ }^{14}$ The participating GPs constituted a representative sample of the total population of Dutch GPs, and their patients have similar demographic characteristics to the general Dutch population. Practices were included in our study if at least $70 \%$ of consultations included a registered diagnosis, and prescription and morbidity data were registered for at least 46 weeks of the year. For the present analysis, 101 practices were available. From these practices, data of all children (0-18 years) with physician-diagnosed fever, ear or respiratory infection (see details below), and a database history of at least one quartile of a year in 2012 were selected.

Our study was carried out according to Dutch legislation on privacy, which instructs that obtaining informed consent and/or approval by medical ethics committee is not obligatory for observational studies. ${ }^{15}$ The NIVEL PCD database includes anonymous information on patients, including their year of birth, dates of consultation, clinical diagnoses (coded with the International Classification of Primary Care version 1 - ICPC-1 scheme) and prescriptions (coded with the Anatomical Therapeutic Chemical - ATC Classification Index). ${ }^{16,17}$ Children were grouped into three age categories: 0 - 4.99 years (early childhood), 5 - 11.99 years (childhood), and 12 - 17.99 years (adolescents) according to national and UNICEF classification. 18-20

The latest versions of the NHG guidelines for 1) fever, 2) acute otitis media (AOM), 3 ) acute cough, 4) acute sore throat and 5) rhinosinusitis were used as pertinent national resources to define fever, ear and respiratory infections and provide guidance on their management. ${ }^{21-25}$ In line with the guidelines, acute cough was subdivided into diagnoses 'pneumonia' and 'acute bronchitis/bronchiolitis', and acute sore throat into diagnoses 'strep throat/scarlet fever' and 'acute tonsillitis (bacterial or viral). Overall, seven ICPC codes were considered sufficiently specific to describe our diagnoses of interest: fever (A03), AOM (H71), strep throat/scarlet fever (R72), sinusitis acute/chronic (R75), acute tonsillitis (R76), acute bronchitis/bronchiolitis (R78) and pneumonia (R81). The studied diagnoses and the recommendations on antibiotic prescribing from the NHG guidelines are summarized in Table S1 (available as Supplementary data at PDIJ Online; http://links.lww.com/INF/C832).

The analysis was based on constructed episodes per ICPC that included all the consultations related to the same health problem within a pre-set time frame. The used algorithm is described elsewhere. ${ }^{13}$ To determine whether and which antibiotics were prescribed per diagnosis, antibiotics (ATC code J01) were linked to ICPC using prescription date and episode start and stop date. If more antibiotics were prescribed during an episode, the first prescription was used for the analysis.

Two sets of disease-specific indicators were used to measure the consistency in antibiotic prescribing between guidelines and GPs prescribing patterns for children in 2012. The first set of indicators examined GP adherence to guidelines on whether or not to prescribe antibiotics for the diagnoses. Antibiotics are generally not recommended for fever and bronchitis/bronchiolitis, so less episodes treated with antibiotics (lower indicator values) mean better adherence to guidelines. In contrast, more episodes of pneumonia treated with antibiotics (higher indicator values) mean 
Ivanovska, V., Hek, K., Mantel-Teeuwisse, A.K., Leufkens, H.G.M., Dijk, L. van. Age-specific antibiotic prescribing and adherence to guidelines in pediatric patients in primary care.

better adherence to guidelines. For diagnoses with restrictive antibiotic use (AOM, strep throat, sinusitis and tonsillitis), percentages of episodes treated with antibiotics may vary according to patient case mix (bacterial or viral etiology, severity of symptoms, risk of complications), so the ideal indicator values could not be specified. The second set of indicators evaluated what antibiotics were prescribed for each of the five ICPCs that would require antibiotics according to the guidelines (H71, R72, R75, R76 and R81). Higher indicator values mean that more first-choice antibiotics were prescribed and thus represent better adherence to guidelines.

\section{Analysis}

At the start, we identified the age-specific advices for antibiotic prescribing in children in the selected NHG guidelines, as presented in Table S1. Next, the incidence rates for each ICPC were calculated per 1,000 person-years by dividing the number of episodes by the total number of person-years in a specific age group. The incidence rates were required to quantify the extent of health problems by age categories and obtain numerators for the indicators.

The first sets of indicators for each age group were calculated by dividing the number of ICPC episodes with an antibiotic prescription by the total number of episodes for that ICPC. The second sets of indicators for each age group were calculated by dividing the number of ICPC episodes prescribed an antibiotic with a specific ATC code by the total number of the ICPC episodes prescribed an antibiotic. Chi-square tests were used to compare differences in the degree of prescribing per diagnosis and first-choice antibiotics between age subgroups. Results with probability level of $\mathrm{p}<0.05$ were considered as statistically significant. Data were analyzed with SPSS version 20.0 (SPSS Inc., Chicago, IL, USA).

\section{RESULTS}

During 2012, the total number of pediatric episodes with fever, ear or RTIs was 13,755. Across all ages, the most frequently reported episodes were related to AOM, fever, acute bronchitis/bronchiolitis and tonsillitis, while pneumonia, sinusitis and strep throat episodes were registered less frequently (Table 1). Table 1 also shows that children in the 0-4 years age group had the highest incidence rates for all studied ICPCs, except for sinusitis. Their most common reasons for GP consultations were AOM, fever and bronchitis/bronchiolitis (199, 135 and 61 episodes per 1,000 personyears, respectively). The 5-11 years age group most frequently reported AOM, tonsillitis and bronchitis (56, 17 and 16 episodes per 1,000 person-years, respectively). Adolescents had the lowest incidence rates for all ICPCs, except for sinusitis. They mostly suffered from tonsillitis, sinusitis and AOM (19, 15 and 14 episodes per 1,000 person- years, respectively).

Figure 1 presents GPs' adherence to recommendations on whether or not antibiotics were prescribed, stratified by ICPC and age. Overall, an antibiotic prescription was registered in $39.5 \%$ of all pediatric episodes, ranging from $36.4 \%$ in the $0-4$ years age group to $51.3 \%$ in the adolescent group. For the majority of clinical conditions that require antibiotics, adolescent episodes were more frequently treated with antibiotics than episodes in the age groups 0-4 years and 5-11 years (strep throat: $76.5 \%$ vs. $55.0 \%$ and $49.5 \%$, pneumonia: $71.6 \%$ vs. $60.2 \%$ and 
Ivanovska, V., Hek, K., Mantel-Teeuwisse, A.K., Leufkens, H.G.M., Dijk, L. van. Age-specific antibiotic prescribing and adherence to guidelines in pediatric patients in primary care.

69.8\%, and tonsillitis: $57.8 \%$ vs. $54.8 \%$ and $49.7 \%$ ). Only for AOM, more episodes in the 0-4 years age group were treated with antibiotics (52.4\%) than in the 5-11 years age group $(39.6 \%)$ and adolescents $(43.9 \%)$. Since antibiotics are recommended for all children younger than two years with bilateral AOM, a subgroup analysis was done in this age group. It showed that $1,008(55.1 \%)$ of 1,831 AOM episodes in children 0-2 years of age were treated with antibiotics, compared to $536(47.9 \%)$ of 1,118 AOM episodes in children 2-4 years of age, respectively. Concerning sinusitis, the small number of episodes in the $0-4$ years age group ruled out any meaningful comparison on antibiotic treatment across age.

For those diagnoses where antibiotics are generally not recommended, more episodes in adolescents were treated with antibiotics as compared with the age groups 0-4 years and 5-11 years (bronchitis: $52.0 \%$ vs. $42.4 \%$ and $42.7 \%$, and fever: $16.8 \%$ vs. $9.0 \%$ and $14.2 \%$ ).

Table 2 shows GP adherence to first-choice antibiotics for diagnoses that require antibiotics, stratified by ICPC and age. AOM episodes in the $0-4$ years age group were more frequently treated with first-choice amoxicillin (88.0\%) compared to episodes in the 5-11 years age group (83.2\%) and adolescents $(81.8 \%)$. Similarly, $74.7 \%$ of pneumonia episodes in the $0-4$ years age group was treated with firstchoice amoxicillin, while the corresponding figures in the 5-11 years age group and adolescents were $57.2 \%$ and $53.8 \%$, respectively. Conversely, more episodes in adolescents were prescribed first-choice narrow-spectrum penicillins than in the age groups 0-4 years and 5-11 years (strep throat: $72.0 \%$ vs. $63.6 \%$, and $60.9 \%$, and tonsillitis: $67.9 \%$ vs. 33.1 and $45.9 \%$ ). Once again, the small number of sinusitis episodes in the age group 0-4 years hampered any meaningful comparison on firstchoice antibiotic treatment across age groups.

First-choice doxycycline for pneumonia and sinusitis (with an age restriction) was not prescribed in any of the children.

\section{DISCUSSION}

Our study showed variation in GP adherence to antibiotic prescribing for fever, ear and respiratory infections in different pediatric age groups. Despite lower consultation frequency, adolescents received antibiotics more commonly, both for episodes when antibiotics are recommended (pneumonia, strep throat, and tonsillitis), or not recommended (bronchitis, fever). The differences in antibiotic treatment rates across ages may reflect the varying role of bacterial and viral infections between specific clinical entities and age groups. The most common causes of pneumonia in infants and preschool children are viruses (respiratory syncytial virus, influenza, parainfluenza virus and human metapneumovirus). In older children, viruses as a sole cause of pneumonia are less common, with the exception of influenza. ${ }^{26}$ These findings may explain the difference in the proportion of pneumonia episodes treated with antibiotics in the oldest $(71.6 \%)$ and youngest age groups $(60.2 \%)$. Also, more frequent referrals of younger children to hospital could lead to an underestimation of antibiotic use in general practice in pneumonia for the 0-4 age group. The NHG guidelines consider a lower threshold for hospital admission of infants below 3 or 6 months of age because they need more supportive care and monitoring, and it is difficult to recognize their subtle, sudden deterioration clinically. ${ }^{23,27}$ When a bacterial cause of pneumonia is found, it is predominantly Streptococcus pneumoniae 
Ivanovska, V., Hek, K., Mantel-Teeuwisse, A.K., Leufkens, H.G.M., Dijk, L. van. Age-specific antibiotic prescribing and adherence to guidelines in pediatric patients in primary care.

in younger children, and Mycoplasma pneumoniae and Chlamydia pneumoniae in older school children and adolescents. ${ }^{26,28,29}$ Such age-specific etiology corresponds to our results on antibiotic selection for pneumonia by age groups. GP adherence to first-choice amoxicillin for S. pneumoniae was highest in children below 5 years (75\%). But, over $40 \%$ in the other two age groups were treated with amoxicillinclavulanate or macrolides (azythromycin, claritromycin) instead, possibly targeting the atypical pathogens. Nonetheless, we could not determine to what extent the choice of antibiotics was consistent with the etiologic agents present in the studied age subpopulations.

These patterns may reflect adolescents' higher threshold of contacting GPs, and that they only went to visit their GPs when the symptoms were relatively severe and/or if there were risk factors for serious disease. We did not assess the presence of comorbidities in different age groups, which may have had an impact on their antibiotic prescribing. Further studies that include data on comorbidities are therefore, needed to potentially interpret (higher) prescribing rates in adolescents. Such analysis could indicate whether guidelines need to address the management of common infections in the subgroup of pediatric patients with chronic diseases. Only in AOM episodes, children 0-4 years of age were prescribed antibiotics more commonly than other age groups. This is consistent with previous Dutch study from 1998, when half of the AOM episodes in children below five years were prescribed antibiotics. ${ }^{30}$ This corresponds to NHG guidelines that recommend antibiotics in all children under two years with bilateral AOM, who have higher risk for bacterial infection. ${ }^{33} \mathrm{GP}$ adherence to first-choice amoxicillin was over $80 \%$ for AOM episodes in all age groups, ensuring a good coverage for its main etiological agent S. pneumoniae.

In the light of current acute cough guidelines, prescribing antibiotics in over $40 \%$ of bronchitis episodes in all children, and more than $50 \%$ in adolescents is unexpectedly high. It is difficult to understand the reasons for such practices, except for (adolescents) higher threshold of contacting GPs, resulting in high-risk samples of patients, where pneumonia or secondary bacterial infections cannot be easily excluded. Also, antibiotics may be requested for the persistent cough that usually accompanies bronchitis, even if that is of no benefit for most cases. Our results may be reflected on in the guidelines by promoting near-patients tests to tackle diagnostic uncertainties for lower RTIs where appropriate, and address patients' concerns and pressure for antibiotics. ${ }^{31}$

Furthermore, this study provides an age-specific insight into the concerning issue of underuse of first-choice narrow-spectrum penicillins (pheneticillin and phenoxymethylpenicillin) for sore throat and tonsillitis. GP adherence to prescribing these antibiotics for tonsillitis episodes was twice as low in children 0-4 years of age compared with the adolescents (33\% vs. 67\%). Instead, over half of tonsillitis episodes in the $0-4$ years age group were treated with amoxicillin or macrolides. The palatable taste of these mixtures (compared to bitter testing penicillin liquids) and their administration frequency convenience improve treatment compliance and are likely explanations for this practice. ${ }^{32,33}$ Additionally, GPs might be inclined to cover a broader spectrum of bacteria than just group A beta haemolytic streptococcus $(G A B H S)$ in the youngest age group. On the contrary, higher percentage of tonsillitis episodes $(67 \%)$ and RTIs episodes $(70 \%)$ were treated with phenoxymethylpenicillin 
Ivanovska, V., Hek, K., Mantel-Teeuwisse, A.K., Leufkens, H.G.M., Dijk, L. van. Age-specific antibiotic prescribing and adherence to guidelines in pediatric patients in primary care.

in the 0-6 years age group in Norway and Sweden respectively. ${ }^{34,35}$ Such differences can be explained by the introduction of the quality indicator " $80 \%$ of antibiotics used to treat RTIs in children 0-6 years of age should be phenoxymethylpenicillin" in the Swedish annual benchmarking of medical treatments and procedures, which may also be considered in the Netherlands. ${ }^{35}$ The main strength of this study is that the data come from a nationwide database, which contains information on diagnoses and prescriptions from a relatively large group of children. Further, individual patient records allow the assessment of the role of child age on disease frequencies and antibiotic prescribing patterns. The age classification can be arbitrary and contextspecific, so our age groups were chosen for better comparability with literature on RTIs.

Since RTIs are often acute, short-term diseases for which patients generally contact the GP only once, we used the first prescription for our analysis. In all age groups, GPs were contacted once in $73.5 \%$ of the episodes, and multiple times in the remaining $26.5 \%$ of the episodes (twice in $16.6 \%$ of the episodes, and three or more times in $9.8 \%$ of the episodes). The number of prescribed antibiotics during these multi-contact episodes was on average 0.7 , as in $88.3 \%$ ofthese episodes 0 or 1 antibiotic was prescribed. ${ }^{13}$ Hence, no considerable difference in prescribing patterns would be expected even if more than one prescription are included in the analysis.

Moreover, our prior analysis of the trend of antibiotic use and compliance to guidelines for all children (0-18 years) in 2010, 2011 and 2012 in the Netherlands has hardly shown any changes over this period. ${ }^{13}$ Therefore, the latest year (2012) was chosen to do this subgroup analysis by age groups.

As described elsewhere, our study has several limitations which are inherent to the use of electronic patient records, such as quality and completeness of the GP records, as well as historic differences in antibiotic prescribing between NIVEL - PCD participating and non-participating GPs. ${ }^{13,36,37}$ It is however, expected that recent policy measures have improved and expanded routine data registration practices at national level. ${ }^{38}$ Our results can be assumed to represent regular GP consultation behavior in the Netherlands as much as possible.

In the present study, we did not control for clustering at practice level because of low patient numbers per age group and per diagnosis. But, our previous research on antibiotic prescribing in all children revealed that levels of adherence to guidelines varied largely between practices, especially for first-choice antibiotics. ${ }^{13}$ Nonetheless, we cannot regard the antibiotic under- and over-use, or choice of antibiotics as

wrong treatment decisions in the absence of clinical golden standards. In some patients, due to clinical characteristics, GPs may have to deviate from the recommendations. However, our results may point out at the following diagnoses and age groups where improvements in prescribing behavior are likely needed. The low adherence to guidelines is worrisome for all children diagnosed with acute bronchitis, and particularly in adolescents; such antibiotic prescribing patterns need more in-depth analysis. Another area to focus future efforts on is the underuse of first-choice narrow-spectrum penicillins in the 0-4 years age group. 
Ivanovska, V., Hek, K., Mantel-Teeuwisse, A.K., Leufkens, H.G.M., Dijk, L. van. Age-specific antibiotic prescribing and adherence to guidelines in pediatric patients in primary care.

Pediatric Infectious Disease Journal: 2018, 37(3), 218-223

\section{REFERENCES:}

Sturkenboom MCJM, Verhamme KMC, Nicolosi A, et al. Drug use in children: cohort study in three European countries. The BMJ. 2008;337:a2245. doi:10.1136/bmj.a2245.

Nash DR, Harman J, Wald ER, et al. Antibiotic prescribing by primary care physicians for children with upper respiratory tract infections. Arch Pediatr Adolesc Med 2002;156:114119

Ciofi degli Atti ML, Massari M, Bella A, et al. Clinical, social and relational determinants of paediatric ambulatory drug presciptions due to respiratory tract infections in Italy. Eur J Clin Pharmacol 2006;62:749-755

Elshout $\mathrm{G}$, van lerland $\mathrm{Y}$, Bohnen $\mathrm{AM}$, et al. Alarm signs and antibiotic prescription in febrile children in primary care: an observational cohort study. Br J Gen Pract. 2013; 63(612): e437-44. doi: 10.3399/bjgp13X669158.

Vernacchio L, Vezina RM, Mitchell AA. Management of acute otitis media by primary care physicians: trends since the release of the 2004 American Academy of Pediatrics/American Academy of Family Physicians clinical practice guideline. Pediatrics. 2007;120:281-287.

Hawker JI, Smith S, Smith GE et al. Trends in antibiotic prescribing in primary care for clinical syndromes subject to national recommendations to reduce antibiotic resistance, UK 1995-2011: analysis of a large database of primary care consultations. J Antimicrob Chemother 2014:69(12):3423-3430

NHG Guidelines. Dutch College of General Practitioners (Netherlands Huisartsen Genootschap). Available at: https://guidelines.nhg.org Accessed April 5, 2015.

Nyquist AC, Gonzales R, Steiner JF, et al. Antibiotic prescribing for children with colds, upper respiratory tract infections, and bronchitis. JAMA. 1998;279(11):875-877

Uijen JHJM, van Duijn HJ, Kuyvenhoven MM, et al. Characteristics of children consulting for cough, sore throat, or earache. Br J Gen Pract 2008;58(549):248-54.

Rogers P. Common Respiratory Infections. In: Strasburger VC, Brown RT, Braverman PK, Rogers PD, Holland-Hall C, Coupey SM, editors. Adolescent medicine: a handbook for primary care. Philadelphia: Lippincott Williams \& Wilkins; 2006. p. 40-46.

Blix HS, Engeland A, Litleskare I, et al. Age- and gender-specific antibacterial prescribing in Norway. J Antimicrob Chemother. 2007;59(5):971-6.

Adriaenssens N, Coenen S, Versporten A et al. European Surveillance of Antimicrobial Consumption (ESAC): outpatient antibiotic use in Europe (1997-2009). J Antimicrob Chemother 2011;66 Suppl 6:vi3-12

Ivanovska V, Hek K, Mantel Teeuwisse AK, et al. Antibiotic prescribing for children in primary care and adherence to treatment guidelines. J Antimicrob Chemother 2016;71(6):17071714.

Netherlands institute for health services research. NIVEL Primary Care Database (NIVEL Zorgregistraties eerste lijn). Available at: http://www.nivel.nl/en/dossier/nivel-primary-caredatabase Accessed April 5, 2015.

Dutch Civil Law, Article 7:458. Available at:

http://www.dutchcivillaw.com/civilcodebook077.htm Accessed April 5, 2015.

Lamberts $\mathrm{H}$, Wood M, Hofman-Okkeks I. The International Classification of Primary Care in the European Community, with a Multilanguage Layer, 1st edition, 1987. Oxford University Press, Oxford, UK

WHO Collaborating Centre for Drug Statistics Methodology. Guidelines for ATC Classification and DDD Assignment 2013. Norwegian Institute of Public health, Oslo, Norway. Available at: http://www.whocc.no/filearchive/publications/1_2013guidelines.pdf Accessed April 5, 2015.

Uijen JHJM, Bindels PJ, Schellevis FG et al. ENT problems in Dutch children: Trends in incidence rates, antibiotic prescribing and referrals 2002-2008. Scand J Prim Health Care 2011;29:75-79.

Bloom B, Jones LI, Freeman G. Summary health statistics for U.S. children: National Health Interview Survey, 2012. Vital Health Stat 2013;10(258). Available at: http://www.cdc.gov/nchs/data/series/sr_10/sr10_258.pdf Accessed April 5, 2015. 
Ivanovska, V., Hek, K., Mantel-Teeuwisse, A.K., Leufkens, H.G.M., Dijk, L. van. Age-specific antibiotic prescribing and adherence to guidelines in pediatric patients in primary care.

Pediatric Infectious Disease Journal: 2018, 37(3), 218-223

UNICEF Situation Report \# 19 - Sub-regional Libya crisis Date: 29 June 2011. Available at: http://reliefweb.int/sites/reliefweb.int/files/resources/Document1_18.pdf Accessed April 5, 2015.

The Dutch College of General Practitioners (NHG) Guidelines. Children with fever (M29), 2008. Available at: http://assortiment.bsl.nl/files/e27c6c2f-8fa3-4f91-9c60-

39597b8ecf7d/voorbeeldhoofdstuk.pdf Accessed April 5, 2015.

The Dutch College of General Practitioners (NHG) Guidelines. Acute otitis media in children (M09), 2006. Available at: http://assortiment.bsl.nl/files/e27c6c2f-8fa3-4f91-9c60-

39597b8ecf7d/voorbeeldhoofdstuk.pdf Accessed April 5, 2015.

The Dutch College of General Practitioners (NHG) Guidelines. Acute cough (M78), 2011

Available at: https://guidelines.nhg.org/product/acute-cough Accessed April 5, 2015.

The Dutch College of General Practitioners (NHG) Guidelines. Acute sore throat (M11), 2007. Available at: https://www.nhg.org/standaarden/volledig/nhg-standaard-acute-keelpijn (in Dutch) Accessed April 5, 2015.

The Dutch College of General Practitioners (NHG) Guidelines. Rhinosinusitis (M33), 2005. Available at: https://www.nhg.org/standaarden/volledig/nhg-standaard-acute-rhinosinusitis (in Dutch) Accessed April 5, 2015.

Farha T, Thomson AH. The burden of pneumonia in children in the developed world.Paediatric Respir Rev 2005;6:76-82.

Le Saux N, Robinson J. Pneumonia in healthy Canadian children and youth: Practice points for management. Paediatrics \& Child Health. 2011;16(7):417-420.

Heiskanen-Kosma T, Korpii M, Jokinen C, et al. Etiology of childhood pneumonia: serologic results of a prospective, population-based study. Pediatr Infect Dis J 1998;17:986-991.

Wubbel L, Muniz L, Ahmed A, et al. Etiology and treatment of community-acquired pneumonia in ambulatory children. Pediatr Infect Dis J 1999;18:98-104.

Jansen AGSK , Sanders EAM , Schilder AGM , et al. Primary care management of respiratory tract infections in Dutch preschool children. Scand J Prim Health Care 2006; 24 : 231-236.

Calls JW, Butler CC, Hopstaken RM, et al. Effect of point of care testing for $\mathrm{C}$ reactive protein and training in communication skills on antibiotic use in lower respiratory tract infections: cluster randomised trial. The BMJ 2009;338:b1374

Petursson P. GPs' reasons for «non-pharmacological» prescribing of antibiotics. A phenomenological study. Scand J Prim Health Care 2005; 23: 120 - 125

Steele RW, Thomas MP, Begue RE. Compliance issues related to the selection of antibiotic suspensions for children. Pediatr Infect Dis J 2001:20(1):1-5.

Fossum GH, Lindbaek M, Gjelstad S et al. Are children carrying the burden of broadspectrum antibiotics in general practice? Prescription pattern for paediatric outpatients with respiratory tract infections in Norway. BMJ Open: 2013;3(1). pii: e002285

SWEDRES-SVARM 2013. Use of antimicrobials and occurrence of antimicrobial resistance in Sweden. Solna/ Uppsala ISSN 1650-6332 Available at:

http://www.sva.se/globalassets/redesign2011/pdf/om_sva/publikationer/swedres_svarm201 3.pdf Accessed April 5, 2015.

Akkerman AE, Kuyvenhoven MM, Verheij TJ et al. Antibiotics in Dutch General Practice: nationwide electronic GP database and national reimbursement rates. Pharmacoepidemiol Drug Saf 2008; 17:378-383.

Westert GP, Hoonhout LHF, de Bakker DH et al. Huisartsen met en zonder elektronisch medisch dossier: weinig verschil in medisch handelen. [General practitioners with and without electronic patient records: little variation in medical care]. Huisarts Wet 2002;45: 58-62 (in Dutch)

van der Bij S, Khan N, ten Veen $\mathrm{P}$ et al. De kwaliteit van elektronische verslaglegging door huisartsen gemeten: EPD-scan regio Twente, eindrapport. [The quality of electronic reporting by GPs. EPD scan region Twente, Final Report] Utrecht; NIVEL, 2013. (in Dutch) Available at: http://www.nivel.nl/sites/default/files/bestanden/Rapport-Kwaliteitelektronische-verslaglegging-Twente.pdf? Accessed April 5, 2015. 
Ivanovska, V., Hek, K., Mantel-Teeuwisse, A.K., Leufkens, H.G.M., Dijk, L. van. Age-specific antibiotic prescribing and adherence to guidelines in pediatric patients in primary care.

\section{TABLES}

Table 1: Fever, ear and RTIs episodes and incidence rates (episodes/1000 personyears) by age groups

\begin{tabular}{|c|c|c|c|}
\hline $\begin{array}{l}\text { Clinical condition } \\
\text { (ICPC) }\end{array}$ & $\begin{array}{l}\text { Age category } \\
\text { (years) }\end{array}$ & $\begin{array}{l}\text { Number of episodes (\% of total } \\
\text { episodes in each age group) }\end{array}$ & $\begin{array}{l}\text { Incidence rates as episodes } \\
\text { per } 1000 \text { person- years }\end{array}$ \\
\hline \multirow[t]{4}{*}{ Fever (A03) } & $0-4$ & 2544 (35.3\%) & 135.1 \\
\hline & $5-11$ & 768 (16.2\%) & 17.0 \\
\hline & $12-17$ & $113(6.3 \%)$ & 4.0 \\
\hline & $0-17$ & 3425 & 41.9 \\
\hline \multirow[t]{4}{*}{ AOM (H71) } & $0-4,99$ & 2949 (40.9\%) & 198.7 \\
\hline & $5-11,99$ & 2222 (46.8\%) & 55.7 \\
\hline & $12-17,99$ & $376(21.0 \%)$ & 13.9 \\
\hline & $0-17,99$ & 5547 & 76.8 \\
\hline \multirow[t]{4}{*}{ Strep throat (R72) } & $0-4,99$ & $60(0.8 \%)$ & 6.6 \\
\hline & $5-11,99$ & $93(2.0 \%)$ & 2.8 \\
\hline & $12-17,99$ & 34 (1.9\%) & 1.7 \\
\hline & $0-17,99$ & 187 & 3.4 \\
\hline \multirow[t]{4}{*}{ Sinusitis (R75) } & $0-4,99$ & $5(0.1 \%)$ & 0.8 \\
\hline & $5-11,99$ & 125 (2.5\%) & 4.2 \\
\hline & $12-17,99$ & 380 (21.2\%) & 15.1 \\
\hline & 0-17,99 & 510 & 7.10 \\
\hline \multirow[t]{4}{*}{ Tonsillitis (R76) } & $0-4,99$ & $442(6.0 \%)$ & 34.8 \\
\hline & $5-11,99$ & $591(12.5 \%)$ & 16.6 \\
\hline & $12-17,99$ & $510(28.4 \%)$ & 19.2 \\
\hline & $0-17,99$ & 1543 & 22.1 \\
\hline \multirow[t]{4}{*}{ Bronchitis (R78) } & $0-4,99$ & 885 (12.3\%) & 60.5 \\
\hline & $5-11,99$ & 579 (12.2\%) & 15.9 \\
\hline & $12-17,99$ & $252(14 \%)$ & 9.9 \\
\hline & $0-17,99$ & 1716 & 24.9 \\
\hline \multirow[t]{4}{*}{ Pneumonia (R81) } & $0-4,99$ & $329(4.6 \%)$ & 24.5 \\
\hline & $5-11,99$ & $368(7.8 \%)$ & 9.9 \\
\hline & $12-17,99$ & $130(7.2 \%)$ & 4.7 \\
\hline & $0-17,99$ & 827 & 11.7 \\
\hline
\end{tabular}


Ivanovska, V., Hek, K., Mantel-Teeuwisse, A.K., Leufkens, H.G.M., Dijk, L. van. Age-specific antibiotic prescribing and adherence to guidelines in pediatric patients in primary care. Pediatric Infectious Disease Journal: 2018, 37(3), 218-223

Table 2: AB choice (\%) for disease episodes according to age groups

\begin{tabular}{|c|c|c|c|c|c|}
\hline \multirow{2}{*}{$\begin{array}{l}\text { ICPC } \\
\text { diagnosis }\end{array}$} & \multirow[t]{2}{*}{ AB treatment } & \multicolumn{3}{|c|}{$\begin{array}{l}\text { Number of episodes (\% of total episodes in each age } \\
\text { group) }\end{array}$} & \multirow{2}{*}{$\begin{array}{l}\text { p-value for differences } \\
\text { between age groups (Chi- } \\
\text { square test) }\end{array}$} \\
\hline & & $0-4$ years & 5-11 years & 12-17 years & \\
\hline \multirow{5}{*}{ H71 (AOM) } & in line with $1^{\text {st }}$ choice & $1359(88.0 \%)$ & $732(83.2 \%)$ & $135(81.8 \%)$ & $\mathrm{p}=0.001$ \\
\hline & in line with $2^{\text {nd }}$ choice & $85(5.5 \%)$ & $59(6.7 \%)$ & $8(4.8 \%)$ & $\mathrm{p}=0.408$ \\
\hline & in line with $1^{\text {st }}$ or $2^{\text {nd }}$ choice & $1444(93.5 \%)$ & $791(89.9 \%)$ & $143(86.7 \%)$ & $\mathrm{p}=0.000$ \\
\hline & Amoxi-clavulanate (J01CR02) & $67(4.3 \%)$ & $53(6,0 \%)$ & $11(6.7 \%)$ & $\mathrm{p}=0.119$ \\
\hline & Clarithromycin (J01FA09) & $26(1.7 \%)$ & $21(2.4 \%)$ & $5(3.0 \%)$ & $\mathrm{p}=0.310$ \\
\hline \multirow{2}{*}{$\begin{array}{c}\text { R72 (Strep } \\
\text { throat) }\end{array}$} & in line with $1^{\text {st }}$ choice & $21(63.6 \%)$ & $28(60.9 \%)$ & $18(72.0 \%)$ & $\mathrm{p}=0.641$ \\
\hline & in line with $2^{\text {nd }}$ choice & $1(3.0 \%)$ & $5(10.9 \%)$ & $2(8.0 \%)$ & $\mathrm{p}=0.434$ (small numbers) \\
\hline \multirow[t]{3}{*}{$N=187$} & in line with $3^{\text {rd }}$ choice & $2(6.0 \%)$ & $3(6.5 \%)$ & $1(4.0 \%)$ & $\mathrm{p}=0.906$ (small numbers) \\
\hline & in line with $1^{\text {st }}$ or $2^{\text {nd }}$ or $3^{\text {rd }}$ choice & $24(72.7 \%)$ & $36(78.3 \%)$ & $21(84.0 \%)$ & $\mathrm{p}=0.590$ \\
\hline & Amoxycillin (J01CA04) & $5(15.2 \%)$ & $9(19.6 \%)$ & $3(12.0 \%)$ & $\mathrm{p}=0.695$ \\
\hline \multirow{5}{*}{$\begin{array}{l}\text { R75 } \\
\text { (Sinusitis) }\end{array}$} & in line with $1^{\text {st }}$ choice & $/ *$ & $43(78.2 \%)$ & $142(74.0 \%)$ & $\mathrm{p}=0.774$ (small numbers) \\
\hline & in line with $2^{\text {nd }}$ choice & $/ *$ & $7(12.7 \%)$ & $25(13.0 \%)$ & $\mathrm{p}=0.799$ (small numbers) \\
\hline & in line with $1^{\text {st }}$ or $2^{\text {nd }}$ choice & $/ *$ & $50(90.9 \%)$ & $167(87.0 \%)$ & $\mathrm{p}=0.400$ (small numbers) \\
\hline & Claritromycin (J01FA09) & $/ *$ & $1(1.8 \%)$ & $9(4.7 \%)$ & $\mathrm{p}=0.594$ (small numbers) \\
\hline & Amoxi-clavulanate (J01CR02) & $/ *$ & $4(7.3 \%)$ & $13(6.8 \%)$ & $\mathrm{p}=0.888$ (small numbers) \\
\hline \multirow{3}{*}{$\begin{array}{c}\text { R76 } \\
\text { (Tonsillitis) }\end{array}$} & in line with $1^{\text {st }}$ choice & $80(33.1 \%)$ & $135(45.9 \%)$ & $200(67.8 \%)$ & $\mathrm{p}=0.000$ \\
\hline & in line with $2^{\text {nd }}$ choice & $25(10.3 \%)$ & $19(6.5 \%)$ & $16(5.4 \%)$ & $\mathrm{p}=0.075$ \\
\hline & in line with $3^{\text {rd }}$ choice & $12(5.0 \%)$ & $21(7.1 \%)$ & $23(7.8 \%)$ & $\mathrm{p}=0.402$ \\
\hline
\end{tabular}


Ivanovska, V., Hek, K., Mantel-Teeuwisse, A.K., Leufkens, H.G.M., Dijk, L. van. Age-specific antibiotic prescribing and adherence to guidelines in pediatric patients in primary care. Pediatric Infectious Disease Journal: 2018, 37(3), 218-223

nivel

\begin{tabular}{|c|c|c|c|c|c|}
\hline \multirow[t]{2}{*}{$N=1543$} & in line with $1^{\text {st }}$ or $2^{\text {nd }}$ or $3^{\text {rd }}$ choice & $117(48.3 \%)$ & $175(59.5 \%)$ & $239(81.0 \%)$ & $\mathrm{p}=0.000$ \\
\hline & Amoxicillin (J01CA04) & $112(46.3 \%)$ & $110(37.4 \%)$ & $39(13.2 \%)$ & $\mathrm{p}=0.000$ \\
\hline \multirow[b]{3}{*}{ (Pneumonia) } & in line with $1^{\text {st }}$ choice & $148(74.7 \%)$ & $147(57.2 \%)$ & $50(53.8 \%)$ & $\mathrm{p}=0.000$ \\
\hline & in line with $2^{\text {nd }}$ choice & $18(9.1 \%)$ & $44(17.1 \%)$ & $11(11.8 \%)$ & $\mathrm{p}=0.040$ \\
\hline & in line with $1^{\text {st }}$ or $2^{\text {nd }}$ choice & $166(83.8 \%)$ & $191(74.3 \%)$ & $61(65.3 \%)$ & $\mathrm{p}=0.002$ \\
\hline \multirow{2}{*}{$N=827$} & Amoxi-clavulanate (J01CR02) & $15(7.6 \%)$ & $35(13.6 \%)$ & $16(17.2 \%)$ & $\mathrm{p}=0.036$ \\
\hline & Claritromycin (J01FA09) & $11(5.6 \%)$ & $21(8.2 \%)$ & $8(8.6 \%)$ & $\mathrm{p}=0.036$ \\
\hline
\end{tabular}

* - Total number of sinusitis episodes in the 0-4 years age group is 5 . 
Ivanovska, V., Hek, K., Mantel-Teeuwisse, A.K., Leufkens, H.G.M., Dijk, L. van. Age-specific antibiotic prescribing and adherence to guidelines in pediatric patients in primary care. Pediatric Infectious Disease Journal: 2018, 37(3), 218-223

Figure 1: Percentages of episodes of fever, ear and respiratory infections treated with antibiotics according to age groups

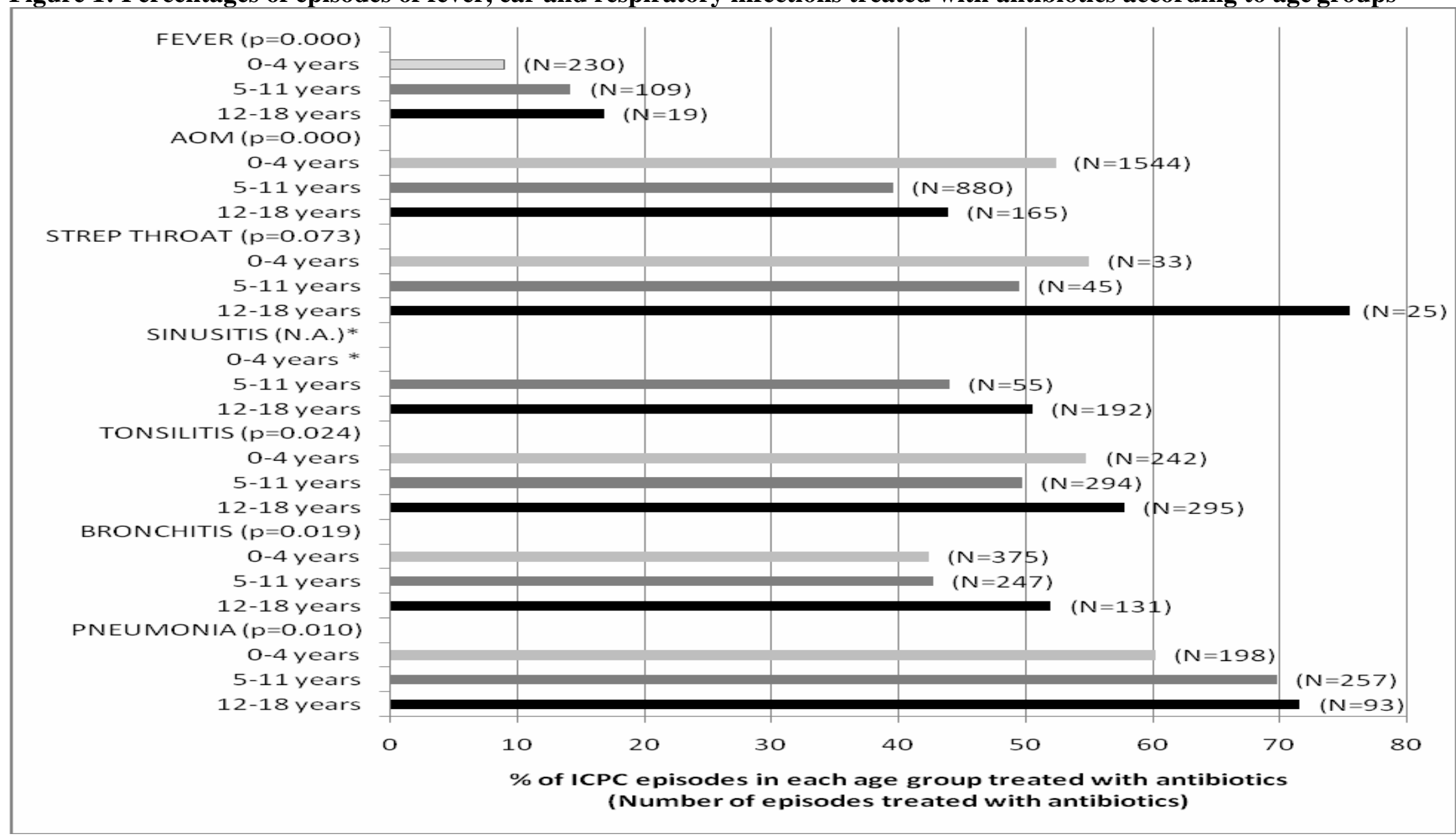

* - Total number of sinusitis episodes in the 0-4 years age group is 5 .

This is a NIVEL certified Post Print, more info at http://www.nivel.eu 